\title{
Air quality and radiative impacts of Arctic shipping emissions in the summertime in northern Norway: from the local to the regional scale
}

Louis Marelle et al.

Correspondence to: Louis Marelle (louis.marelle@latmos.ipsl.fr) and Jennie L. Thomas (jennie.thomas@latmos.ipsl.fr)

The copyright of individual parts of the supplement might differ from the CC-BY 3.0 licence. 

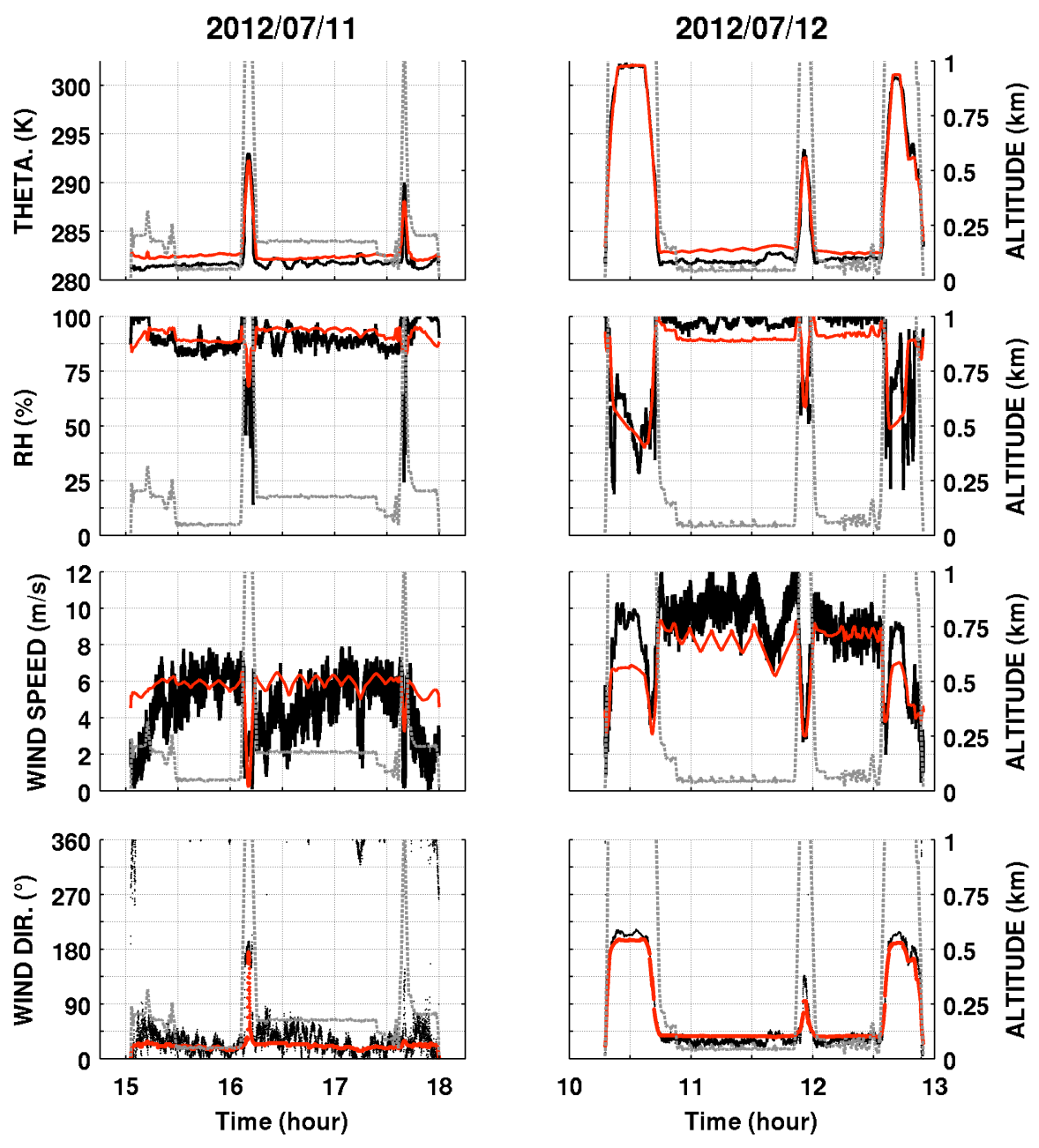

MODEL

OBS

ALTITUDE

Figure S1. ACCESS measurements of potential temperature, relative humidity, wind speed and wind direction (black) for the 11 and 12 July flights, compared with WRF-Chem MET simulation results interpolated along the flight track for the same flights (red). 

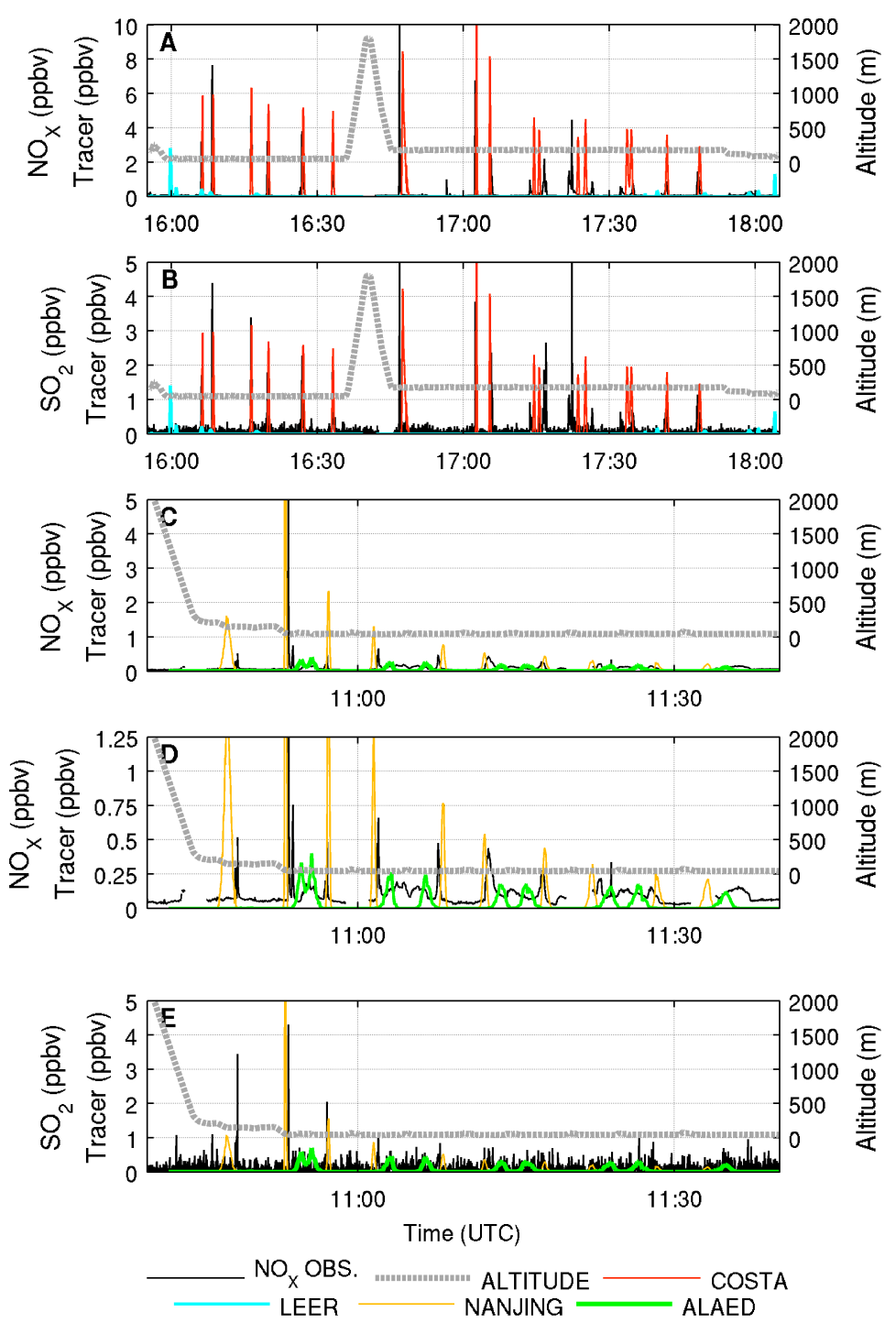

Figure S2. (a, c, d) $\mathrm{NO}_{\mathrm{x}}$ and (b, e) $\mathrm{SO}_{2}$ aircraft measurements (black) compared to FLEXPART-WRF air tracer mixing ratios interpolated along flight tracks, for the plumes of the (a, b) Costa Deliziosa and Wilson Leer on 11 July 2012 (showing the 2 constant altitude levels at $\mathrm{Z} \sim 49 \mathrm{~m}$ and $\mathrm{Z} \sim 165 \mathrm{~m}$ ) (c, d, e) Wilson Nanjing and Alaed on 12 July 2012. Panel (d) shows the same results as Panel (c), zoomed in. Since model results depend linearly on the emission flux chosen a priori for each ship, model results have been scaled so that peak heights are comparable to the measurements. 

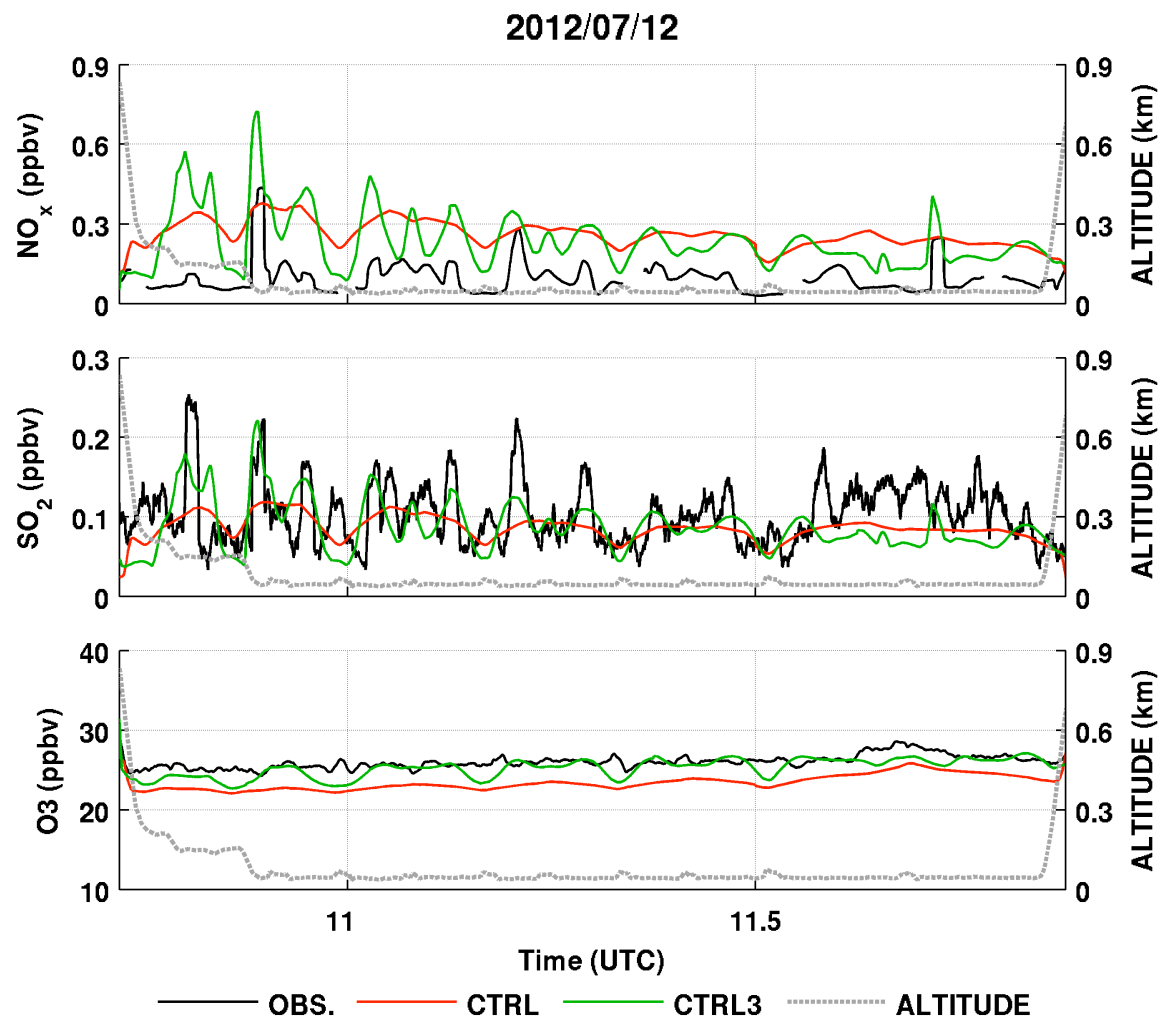

Figure S3. Time series of measured $\mathrm{NO}_{\mathrm{x}}, \mathrm{SO}_{2}$ and $\mathrm{O}_{3}$ on 12 July 2012 compared to model results extracted along the flight track for the CTRL and CTRL3 runs. Observations are in black, the CTRL run is in red, and the CTRL3 run is in green. A 56 s averaging window is applied to the measured data for model comparison (approximately the time for the aircraft to travel $2 \times 3 \mathrm{~km})$. Flight altitude is given as dashed gray line. 

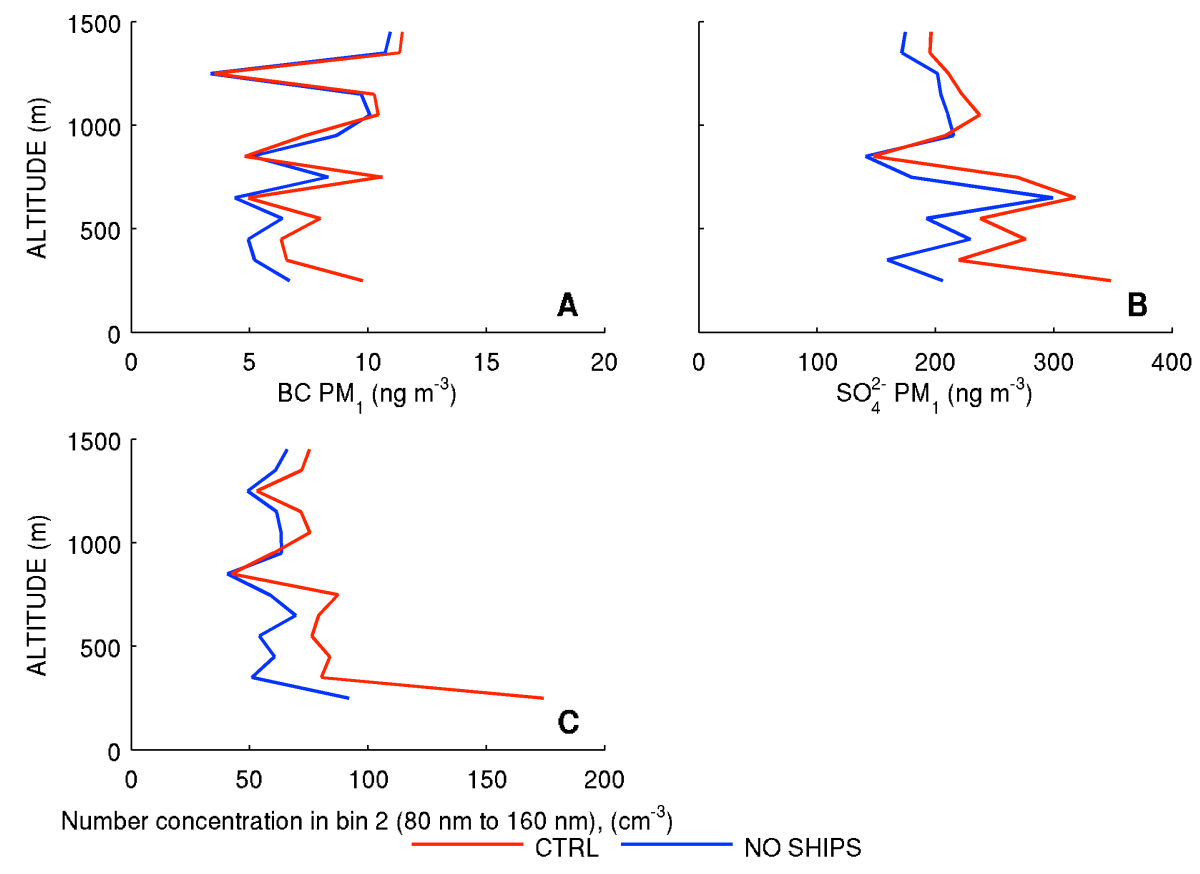

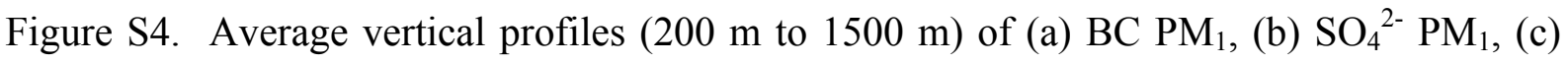
number concentrations in the second bin of MOSAIC (diameters $78 \mathrm{~nm}$ to $156 \mathrm{~nm}$ ), interpolated along the ACCESS flight tracks for the 4 ship flights in the CTRL simulation (red line) and in the NOSHIPS simulation (blue line). 